\title{
Accessory Liver Lobe Attached to the Wall of the Gallbladder
}

\author{
Ariel H. Park ${ }^{1}$, Tien-Anh Tran $^{2}$, Vladimir Neychev ${ }^{3}$ \\ 1. Medicine, University of Central Florida College of Medicine, Orlando, USA 2. Pathology, AdventHealth Orlando, \\ Orlando, USA 3. Surgery, University of Central Florida College of Medicine, Orlando, USA
}

Corresponding author: Ariel H. Park, arielhyewonpark@knights.ucf.edu

\begin{abstract}
A 47-year-old woman with a history of known gallstone disease presented with worsening post-prandial right upper abdominal pain radiating to the back, abdominal bloating, and nausea. An ultrasound of the abdomen confirmed the diagnosis of cholelithiasis. During laparoscopic cholecystectomy, an accessory liver lobe attached to the anterior wall of the gallbladder was incidentally found. An accessory liver lobe is a rare anatomical variation that mostly remains clinically asymptomatic. Since hepatocellular carcinoma can rarely develop in an accessory liver lobe, intraoperative complete resection should be considered for both therapeutic and diagnostic purposes.
\end{abstract}

Categories: Gastroenterology, General Surgery, Anatomy Keywords: liver, accessory liver, hepatocellular carcinoma

\section{Introduction}

An accessory liver lobe (AL) is a rare congenital anomaly generally due to either defective or excessive development of the liver [1]. It was first described as a lobe of the liver connected to the main liver via a dense membrane by Morgagni in 1767 [2]. Although it can rarely cause abdominal pain and liver dysfunction, AL mostly remains asymptomatic and is commonly found incidentally during laparotomy, autopsy, and radiologic studies [1]. We report a case of an ectopic AL that was incidentally found to be attached to the anterior surface of the gallbladder wall during laparoscopic cholecystectomy.

Received 11/05/2019 Review began 11/05/2019 Review ended 11/09/2019 Published 11/10/2019

(c) Copyright 2019

Park et al. This is an open access article distributed under the terms of the Creative Commons Attribution License CC-BY 3.0., which permits unrestricted use, distribution, and reproduction in any medium, provided the original author and source are credited.

\section{Case Presentation}

A 47-year-old woman with a history of known gallstone disease presented to the office with worsening postprandial right upper abdominal pain radiating to the back, abdominal bloating, and nausea. Her clinical history was significant for hypertension, hyperlipidemia, and tubal ligation. Her vitals were within normal limits, and physical examination showed mild right upper quadrant tenderness without rebound or Murphy's sign. Laboratory studies including complete blood cell count, liver function tests, and coagulation panel were within normal limits. An ultrasound of the abdomen confirmed the diagnosis of cholelithiasis (Figure $1 \mathrm{~A}, 1 \mathrm{~B})$. There was no indication of an AL on the ultrasound images. After a detailed discussion about the biology, natural history, and management options of gallstone disease, including risks and benefits of operative vs non-operative approaches, a decision was made to proceed with an elective laparoscopic cholecystectomy. During the laparoscopic exploration of the Morrison’s space, an approximately $2 \mathrm{~cm}$ ellipsoid structure similar in color and consistency to the liver was found attached to the serosal surface of the anteromedial wall of the gallbladder (Figure $1 C, 1 D$ ). 


\section{Cureus}
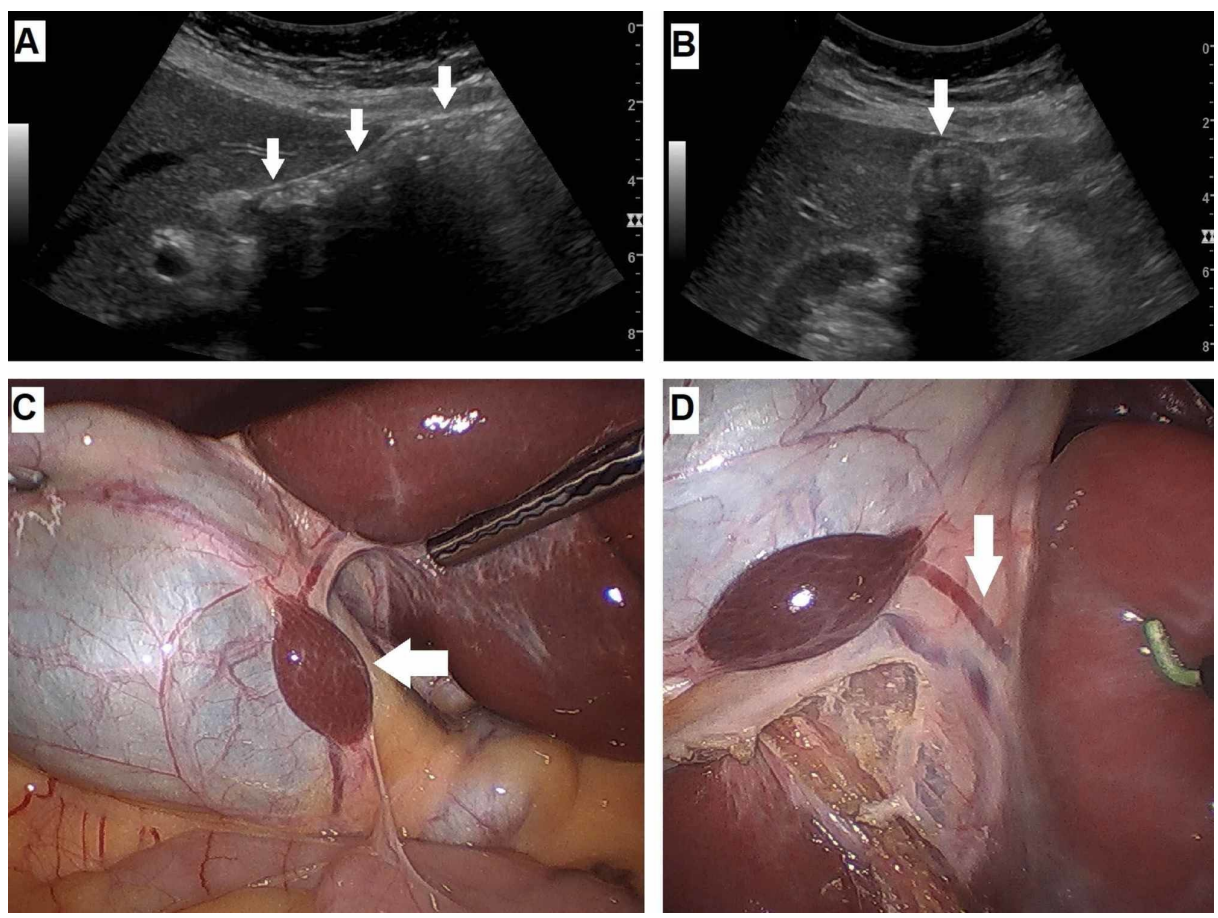

\section{FIGURE 1: Ultrasound images and intraoperative findings}

A, Sagittal and B, Transverse ultrasonography images of multiple gallstones represented by reflective echogenic foci within gallbladder lumen with prominent posterior acoustic shadowing (arrows). C, Intraoperative laparoscopic view of the gallbladder retracted over the anterior edge of the liver, revealing an encapsulated accessory liver lobe on the serosal surface of the anteromedial gallbladder wall (arrow). D, Arrow points at a separate vascular pedicle draining the accessory liver lobe well visualized after the mobilization and dissection of the gallbladder from its liver bed.

This finding was consistent with the diagnosis of an AL with its own vascular pedicle. After achieving the critical view of safety, the cystic duct, cystic artery, and the vascular pedicle of the AL were secured with laparoscopic endoclips and transected. The AL was dissected en block with the gallbladder off the liver bed. The patient tolerated and recovered from the procedure well, and she was discharged to home on the day of surgery without complications.

In addition to several choleliths, gross examination of the gallbladder revealed a $1.4 \times 0.9 \times 0.4 \mathrm{~cm}$ encapsulated fragment of brown soft tissue resembling liver tissue on the serosa (Figure 2A). Histologic examination demonstrated characteristic liver architecture including liver cell cords and sinuses and defined portal tracts containing all three major structures: portal venule, hepatic arteriole, and interlobular bile duct (Figure 2B). The histologic findings supported the diagnosis of an AL. Of note, the AL was located $0.1 \mathrm{~cm}$ from the true liver bed of the gallbladder.

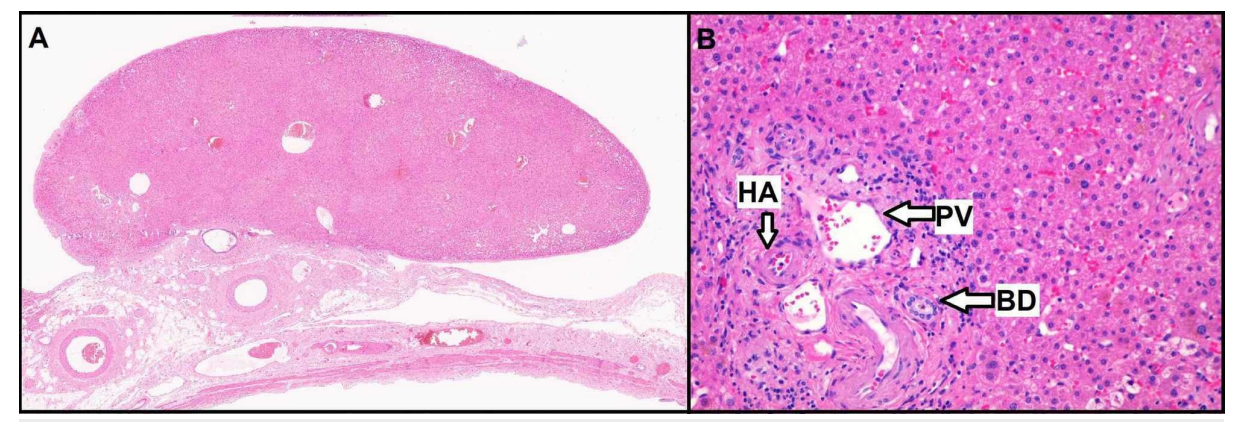

\section{FIGURE 2: Surgical H\&E histopathology}

A, Low power of the accessory liver lobe attached to the serosal surface of the anterior gallbladder wall. B, High power (x200) of the accessory liver lobe showing portal triad, contains three major structures: portal vein (PV), hepatic artery (HA), and bile ductule (BD). 


\section{Discussion}

An AL is a rare morphologic variation of hepatic tissue usually detected during surgery or autopsy [1]. Most AL result from embryonic heteroplasia but can also rarely occur after trauma or surgery [3]. Two etiological hypotheses have been postulated: (1) a part of the developing liver is entrapped in the septum transversum and subsequently pulled by the weight of intra-abdominal liver, and (2) formation of an AL due to an increased intra-abdominal pressure caused by the development of tunica muscularis recti and enlargement of the liver $[4,5]$.

Different classifications of the AL are documented in the literature. One such classification recognizes three broad types based on the gross anatomical connection of AL to the liver: (1) AL attached to the liver via a stalk; (2) AL representing a tongue-like projection of the anterior edge of the liver without a defined stalk (Riedel's lobe); and (3) ectopic AL located outside the liver without any connections to the liver [6,7]. Another classification system takes into account the different anatomical variants of the connection between the AL bile duct and the intrahepatic or extrahepatic main biliary tree: (1) AL with a separate accessory lobe duct draining into an intrahepatic bile duct of the liver; (2) AL with a separate accessory lobe duct draining into an extrahepatic bile duct of the liver; and (3) AL with a common capsule with the normal liver and the bile duct draining into an extrahepatic duct [8].

In most cases, AL is located in the infrahepatic location but also can be found at the gastrohepatic ligament, near the umbilicus, adrenal glands, spleen, pancreas, or gallbladder as presented in this case [9]. In addition, ectopic AL has also been reported in extra-abdominal sites such as intrathoracic cavity, vena cava, heart, or lung [10].

The true incidence of all types of AL has been difficult to determine due to its rarity. A laparoscopic observational study revealed the incidence of AL and ectopic liver to be $0.7 \%$ [11]. Earlier studies reported the incidence rate of Riedel's lobe to range broadly from 3.3\% to $14.5 \%[12,13]$. Although most AL cases are discovered incidentally during unrelated surgeries, some cases were also found preoperatively on ultrasound or CT images performed for acute abdominal pain or pulmonary symptoms $[14,15]$.

Most patients with an AL remain asymptomatic but rarely can present with acute or recurring abdominal pain, precordial pain, nausea, or vomiting [14]. AL can also lead to complications including torsion, traumatic rupture, infarction, or even more seriously, liver dysfunction or hepatocellular carcinoma formation $[9,16]$. Extrahepatic AL is believed to have an increased risk of neoplasm due to its incomplete metabolic function and abnormal architecture of arterial supply and venous and biliary drainage [17]. Hepatocellular carcinoma arising in an AL is usually limited to the ectopic AL, and therefore is commonly associated with a favorable prognosis as complete resection of the carcinoma is considered curative [18].

\section{Conclusions}

AL are rare anatomic anomalies that are usually found incidentally during surgery. Although they mostly remain clinically silent, AL has been reportedly associated with the development of hepatocellular carcinoma. Thus, it is important to be aware of, recognize, and resect AL when found preoperatively or incidentally during unrelated surgical procedures.

\section{Additional Information \\ Disclosures}

Human subjects: Consent was obtained by all participants in this study. Conflicts of interest: In compliance with the ICMJE uniform disclosure form, all authors declare the following: Payment/services info: All authors have declared that no financial support was received from any organization for the submitted work. Financial relationships: All authors have declared that they have no financial relationships at present or within the previous three years with any organizations that might have an interest in the submitted work. Other relationships: All authors have declared that there are no other relationships or activities that could appear to have influenced the submitted work.

\section{References}

1. Ladurner R, Brandacher G, Mark W, et al.: Complete hepatic ischemia due to torsion of a large accessory liver lobe: first case to require transplantation. Transpl Int. 2005, 18:467-469. 10.1111/j.14322277.2005.00072.x

2. Morgagni JB cited by Forni (ed): De sedibus et causis morborum. Epistolae II . 1767, 48:55.

3. Tancredi A, Cuttitta A, de Martino DG, Scaramuzzi R: Ectopic hepatic tissue misdiagnosed as a tumor of lung. Updates Surg. 2010, 62:121-123. 10.1007/s13304-010-0016-9

4. Ito F, Ando H, Watanabe Y, et al.: An accessory lobe of the liver disturbing closure of the umbilical ring . Pediatr Surg Int. 1999, 15:394-396. 10.1007/s003830050609

5. Nora E, Carr CE: Umbilical accessory liver. Am J Obstet Gynecol. 1946, 52:330-335. 10.1016/s00029378(16)39845-3

6. Khan AM, Hundal R, Manzoor K, Dhuper S, Korsten MA: Accessory liver lobes: a diagnostic and therapeutic 


\section{Cureus}

challenge of their torsions. Scand J Gastroenterol. 2006, 41:125-130. 10.1080/00365520500377862

7. Glenisson M, Salloum C, Lim C, et al.: Accessory liver lobes: anatomical description and clinical implications. J Visc Surg. 2014, 151:451-455. 10.1016/j.jviscsurg.2014.09.013

8. Elmasalme F, Aljudaibi A, Matbouly S, Hejazi N, Zuberi MS: Torsion of an accessory lobe of the liver in an infant. J Pediatr Surg. 1995, 30:1348-1350. 10.1016/0022-3468(95)90502-2

9. Anand SS, Chauhan MS: Intrathoracic accessory lobe of the liver . Int J Nucl Med. 2002, 17:44-45.

10. Park WH, Choi SO, Lee SS, Randolph JG: Ectopic umbilical liver in conjunction with biliary atresia: uncommon association. J Pediatr Surg. 1991, 26:219-222. 10.1016/0022-3468(91)90917-i

11. Sato S, Watanabe M, Nagasawa S, Niigaki M, Sakai S, Akagi S: Laparoscopic observations of congenital anomalies of the liver. Gastrointest Endosc. 1998, 47:136-140. 10.1016/s0016-5107(98)70345-1

12. Sham R, Sain A, Silver L: Hypertrophic Riedel's lobe of the liver. Clin Nucl Med. 1978, 3:79-81. 10.1097/00003072-197803000-00001

13. Mould RF: An investigation of the variations in normal liver shape . Br J Radiol. 1972, 45:586-590. 10.1259/0007-1285-45-536-586

14. Wang C, Cheng L, Zhang Z, et al.: Accessory lobes of the liver: a report of 3 cases and review of the literature. Intractable Rare Dis Res. 2012, 1:86-91. 10.5582/irdr.2012.v1.2.86

15. Koplewitz BZ, Manson DE, Ein SH: Posttraumatic torsion of accessory lobe of the liver and the gallbladder . Pediatr Radiol. 1999, 29:799-802. 10.1007/s002470050698

16. Garba ES, Ameh EA: Isolated rupture of an accessory liver from blunt abdominal trauma in childhood . Pediatr Surg Int. 2002, 18:62-63. 10.1007/s003830200014

17. Arakawa M, Kimura Y, Sakata K, Kubo Y, Fukushima T, Okuda K: Propensity of ectopic liver to hepatocarcinogenesis: case reports and a review of the literature. Hepatology. 1999, 29:57-61. 10.1002/hep.510290144

18. Seo UH, Lee HJ, Ryu WS, et al.: Laparoscopic resection of a hepatocellular carcinoma arising from an ectopic liver. Surg Laparosc Endosc Percutan Tech. 2008, 18:508-510. 10.1097/SLE.0b013e31817e920f 